\title{
A Biomechanical Analysis of Dumbbell Curl and Investigation of the Effects of Increasing Loads on Biceps Brachii Using A Finite Element Model
}

Kasim Serbest ( $\sim$ kserbest@subu.edu.tr)

Sakarya Uygulamali Bilimler Universitesi https://orcid.org/0000-0002-0064-4020

\section{Research Article}

Keywords: Dumbbell curl, biceps brachii, increasing training load, muscle force, finite element model

Posted Date: February 2nd, 2022

DOI: https://doi.org/10.21203/rs.3.rs-1263844/v1

License: (c) (1) This work is licensed under a Creative Commons Attribution 4.0 International License.

Read Full License 


\section{Abstract}

Dumbbell curl is one of the most important strengthening exercises for the upper extremity. This exercise trains especially biceps brachii. Exercise load is increased to achieve more muscle strength for the biceps brachii. Researchers are usually focused on electromyography (EMG) in order to examine the effects of load increasing on muscle contraction. However, only the muscle force can be predicted with EMG measurement. Structural analysis of the muscles cannot be performed. In this study, the effects of load increasing on biceps brachii were investigated by mechanical analysis. The inverse dynamic model was simulated according to the motion analysis of dumbbell curl exercises performed with $6 \mathrm{~kg}$ and $10.7 \mathrm{~kg}$. The muscle force of the biceps brachii was calculated from the elbow joint reaction moment. A simplified finite element model of biceps brachii was created and stress-strain response was examined. Although the muscle force increases by $78.3 \%$, the rate of increase of elbow peak moment is $57.7 \%$ and the rate of increase of peak muscle force is $38.3 \%$. Similarly, the rate of increase of maximum strain and maximum stress are $44.4 \%$ and $37.3 \%$, respectively. According to these results, it is understood that increasing the dumbbell load does not increase the muscle force at the same rate.

\section{Introduction}

Dumbbell curl or biceps curl is a basic exercise to strengthen upper extremity muscles. The movement pattern of this exercise, which can be performed in different posture positions or with different equipment, is generally the same. The movement is started when the elbow joint is in full extension and the forearm is flexed until dumbbells reach the top of the shoulders. Then arms return to the starting position. The elbows keep close to the body during the movement. The forearm and upper arm muscles are strengthened with repeated movements. The most contraction occurs in biceps brachii during the dumbbell curl exercise (Stiggins and Allsen, 1985).

Exercises are done with dumbbells of different weights and different repetitions to strengthen the biceps brachii. It is necessary to know the effects of dumbbell curl movement on biceps brachii to prevent muscle damage and to provide an effective exercise. Hwang et al. (2016) used electromyography (EMG) to determine muscle fatigue during dumbbell curl exercise. Garcia-Manso et al. (2012) examined the effects of biceps curl exercises on muscles with $10 \mathrm{~kg}$ and $30 \mathrm{~kg}$ loads by tensiomyography method. Cha et al. (2015) predicted muscle activation and muscle moments in different dumbbell load using EMG signals.

There are different simulation models and software for biomechanical analysis of exercise movements and prediction of muscle force (Karimi et al. 2021; Trinler et al., 2019; Cadova et al.2014; Bogert et al., 2013; Tang et al., 2012; Nolte et. al, 2011). In addition, finite element models are used for structural analysis of skeletal muscles such as stress, strain and deformation. Oomens et al. (2003) studied the anterior tibialis strain of a rat under constant load using a 2D continuum model. Blemker et al. (2005) investigated non-uniform strain on a 3-dimensional model of biceps brachii. Martins et al. (2006) analysed the continuum deformations in skeletal muscles using 2D and 3D finite element models 
according to the Hill-type muscle model. Webb et al. (2014) calculated the moment arm distance of the muscles with a 3D finite element model. Rohrle et al. (2017) studied the stress and displacement in the muscles using the continuum-mechanical forward simulation method.

The intensity of muscle contraction can be calculated in analysis using EMG (Karimi, et al. 2021). Additionally, muscle force can be estimated during contraction. However, the deformation on the muscle and the tendon cannot be determined clearly. Finite element models give useful results in determining the muscle deformation. It is shown that muscle force is held constant in previous studies on finite element models. The peak stress or the deformation of the muscle can be calculated in the analysis using the peak muscle force. However, muscle force is variable during the exercises. Therefore, the force applied to the muscles should vary according to the movement pattern for accurate analysis.

This study aimed to investigate the mechanical effects of the dumbbell curl exercise performed with different loads on the biceps brachii. In addition, it is aimed to understand whether the relationship between dumbbell load increase and muscle force is linear. First of all, the dynamic muscle force during the dumbbell curl exercise was calculated via an inverse dynamic simulation model. Then, the effects of dynamic muscle force on the biceps brachii were investigated with a simplified 3D finite element model. As a result of the analyses, the strain and stress on biceps brachii were calculated.

\section{Methodology}

Firstly, the motion analysis of the dumbbell curl exercise was performed in this study. The displacement of the upper extremity joints was determined using two different dumbbell load on a volunteer subject. the Sakarya University Ethical Committee approved this study (number: 71522473/050.01.04/94). Then, the dumbbell curl exercise was simulated in MATLAB environment using the motion data of the joints. As a result of simulation, the biceps brachii contraction force was calculated. Structural analysis of muscle force on biceps brachii was examined with a finite element model based on muscle and tendon material properties. Figure 1 shows the flowchart of the study. Details of the above are included in the following sections.

\subsection{Motion Analysis of Dumbbell Curl}

Dumbbell curl exercises were performed by a male subject (33 years, height $174 \mathrm{~cm}$ and mass $73 \mathrm{~kg}$ ) with a training background. Passive markers were placed on the dumbbell bar, elbow and shoulder joints of the subject. The volunteer performed the dumbbell exercise in standing position according to (Stiggins and Allsen, 1985). The exercise was done with $6 \mathrm{~kg}$ and $10.7 \mathrm{~kg}$ dumbbells. The subject completed 3 repetitions for each load with a self-selected speed. Markers motion were captured with a digital video camera which has $30 \mathrm{~Hz}$ image frequency. Tracker video analysis software was used for digitization (Brown, 2008). The angular displacement, angular velocity and angular acceleration of the elbow joint were calculated using the motion data of the markers.

\subsection{Simulation Model of the Dumbbell Curl}


An inverse dynamic joint limb model has been created to simulate the dumbbell curl exercise. The model consists of dumbbell, forearm, upper arm, elbow and shoulder joints. In addition, the biceps brachii is modelled as a spring-damper element according to the Hill-type muscle model (Winters and Woo, 1990). The joint limb model is shown in Figure 2.

Muscle contraction force according to the Hill-type muscle model can be expressed in Eq. (1). where $F$ is muscle tensile force, $v$ is muscle shortening velocity, $F_{\max }$ is the maximum isometric force, $a$ and $b$ are constants. Muscle force of biceps brachii also causes a moment on the elbow joint during the dumbbell curl (Eq. 2). where $M$ is joint reaction moment and $d$ is the distance of biceps brachii moment arm.

$$
(\vec{F}+a)(\vec{v}+b)=\left(\vec{F}_{\text {max }}+a\right) b
$$

1

$$
\vec{M}=\vec{F} \cdot d
$$

Solving Eq. (1) is a challenging process. Instead, muscle force was calculated using Eq. (2) in this study. Here, $d$ changes according to the elbow joint angle. In our study, $d$ is adapted from (Delp et al., 2007). Elbow joint moment was calculated by simulating the dumbbell curl exercise. Then, muscle force was found solving Eq. (2).

Simulation process was done using MATLAB Multibody tools (Figure 3). Body segments are modelled as a rigid body in the MATLAB simulation. The elbow joint is modelled as a single degree of freedom revolute joint. The shoulder and ankle joint are each considered as a fixed joint. Biceps brachii is modelled as a spring-damping element between the elbow and the shoulder joints. Stiffness of biceps brachii ( $k$ ) is adapted from (Agyapong-Badu et al., 2016) as a $213 \mathrm{~N} / \mathrm{m}$. Damper constant (b) and muscletendon length of biceps brachii are adapted from (Winters and Woo, 1990) as $6.44 \mathrm{Ns} / \mathrm{m}$ and $0.312 \mathrm{~m}$, respectively. The moment of inertia of the body segment was calculated according to the equations from (Chandler et al., 1975). Segment length, mass and centre of mass were calculated from (Winter, 1990). Table 1 shows mass and inertial parameters. 
Table 1

Body and segment parameters of the limbs and dumbbell. The centre of mass is given by the proximal end of the limb. a; forearm and hand are considered together.

\begin{tabular}{|c|c|c|c|c|c|c|}
\hline \multirow[t]{2}{*}{ Body } & \multirow{2}{*}{$\begin{array}{l}\text { Length } \\
\text { (m) }\end{array}$} & \multirow{2}{*}{$\begin{array}{l}\text { Mass } \\
(\mathrm{kg})\end{array}$} & \multicolumn{3}{|c|}{ Moment of Inertia $\left(x 10^{-4} \mathrm{~kg} \cdot \mathrm{m}^{2}\right)$} & \multirow{2}{*}{$\begin{array}{l}\text { Centre of mass } \\
\text { (m) }\end{array}$} \\
\hline & & & $\mathrm{I}_{\mathrm{xx}}$ & $\mathrm{I}_{\mathrm{yy}}$ & $\mathrm{I}_{\mathrm{zz}}$ & \\
\hline Forearma & 0.299 & 1.606 & 75.123 & 11.932 & 77.409 & 0.153 \\
\hline Upper arm & 0.356 & 2.044 & 148.268 & 27.200 & 168.577 & 0.130 \\
\hline Bar part 1 & 0.145 & 0.400 & 7.492 & 7.492 & 9.680 & Midpoint \\
\hline Bar part 2 & 0.105 & 0.3 & 3.119 & 3.119 & 7.260 & Midpoint \\
\hline Bar part 3 & 0.145 & 0.400 & 7.492 & 7.492 & 9.680 & Midpoint \\
\hline Weight plate1 & 0.022 & 2.000 & 0.289 & 0.289 & 0.562 & Midpoint \\
\hline Weight plate2 & 0.022 & 2.500 & 0.410 & 0.410 & 0.800 & Midpoint \\
\hline
\end{tabular}

The inverse dynamic model (see Figure 2 and 3 ) can be solved according to the principle of conservation of angular momentum in Eq. (3) below:

$$
\sum_{i=1}^{i=3} M_{i}=I_{i} \bullet \ddot{\theta}_{i}
$$

where $M$ is joints moment, $I$ is moment of inertia of the segments and $\theta$ is angular displacement of the joints. Reaction moment in each joint can be calculated by Eq. (4) below:

$$
\left[\begin{array}{l}
I_{1, x x} I_{1, y y} I_{1, z z} \\
I_{2, x x} I_{2, y y} I_{2, z z} \\
I_{3, x x} I_{3, y y} I_{3, z z}
\end{array}\right]\left[\begin{array}{l}
\ddot{\theta}_{1, z} \\
\ddot{\theta}_{2, z} \\
\ddot{\theta}_{3, z}
\end{array}\right]=\left[\begin{array}{l}
M_{1, z} \\
M_{2, z} \\
M_{3, z}
\end{array}\right]
$$

where $x, y$ and $z$ are reference axes. Since the shoulder joint is assumed to be a fixed joint and the dumbbell is fixed to the wrist joint, $M_{1}$ and $M_{3}$ will be zero. As a result of the simulation, the elbow reaction moment $M_{2}$ was calculated. Then, muscle force was calculated by Eq. (2) during the dumbbell curl exercise.

\subsection{Finite Element Model of the Biceps Brachii}


After calculating the muscle force during the dumbbell curl exercise, the stress and strain response of the biceps brachii were analysed using a finite element model. A simplified finite element model according to the muscle and tendon properties of the biceps brachii is shown in Figure 4. Here tendon length $\left(L_{t}\right)$ is $0.0625 \mathrm{~m}$ (Giat, 1990), total length of muscle $\left(L_{m}\right)$ is $0.312 \mathrm{~m}$ (Winters and Woo, 1990), $D_{1}$ is $0.014 \mathrm{~m}$ and $D_{2}$ is $0.042 \mathrm{~m}$ (Bol and Reese, 2008). The material properties of the muscle were assumed as follows. Density was $1056 \mathrm{~kg} / \mathrm{m}^{3}$, Poisson's ratio was 0.4 and Young's modulus was $1.162 \cdot 10^{6} \mathrm{~Pa}$ (AlObaid et al., 2007). The material properties of the tendon were assumed as follows. Density was 1670 $\mathrm{kg} / \mathrm{m}^{3}$, Poisson's ratio was 0.497 and Young's modulus was $1.6 \cdot 10^{6} \mathrm{~Pa}$ (Lewis and Shaw, 1997). A hexahedral mesh consisting of 18428 nodes and 3906 elements was used in the finite element model created in the ANSYS Workbench environment. The model was fixed at the end of the tendon and the dynamic force calculated by dumbbell curl simulation was applied from the tip of the muscle. As a result of the analysis, the strain and stress response of the muscle were calculated.

Due to the different material properties of the muscle and the tendon, total stress $\left(\sigma_{T}\right)$ can be expressed in Eq. (5) and total strain $\left(\epsilon_{T}\right)$ can be expressed in Eq. (6) where $\sigma_{t}$ is tendon stress, $\sigma_{m}$ is muscle stress, $\epsilon_{t}$ is tendon strain and $\epsilon_{m}$ is muscle strain.

$$
\sigma_{T}=\sigma_{t}+\sigma_{m}
$$

5

$$
\epsilon_{T}=\epsilon_{t}+\epsilon_{m}
$$

6

\section{Results}

The maximum displacement in the biceps curl movement performed with $6 \mathrm{~kg}$ and $10.7 \mathrm{~kg}$ dumbbells was measured at the elbow joint. Shoulder joint has been regarded as fixed because of a small displacement. The angular displacement and angular velocity of the elbow joint with different load can be seen in Figure 5.

The inverse dynamic model was simulated by using the motion data. As a result of the simulation, the joint moment of elbow was calculated. Then, muscle force of the biceps brachii was determined according to changing moment arm. Figure 6 shows the variation of elbow joint moment and biceps brachii force in two different loads.

After calculating the biceps brachii force, the finite element model was analysed. Strain (Figure 7) and stress (Figure 8) responses of the biceps brachii were analysed using variable muscle force.

\section{Discussion}


It is seen that the behaviour of the displacement and the velocity are almost the same in both dumbbell loads (see Fig. 5). Thus, the only parameter which affects joint moment is increasing dumbbell load.

The peak joint moment was calculated to be $18.88 \mathrm{Nm}$ with $6 \mathrm{~kg}$ dumbbell and $29.78 \mathrm{Nm}$ with $10.7 \mathrm{~kg}$ dumbbell. The peak muscle force was calculated to be $645.66 \mathrm{~N}$ with $6 \mathrm{~kg}$ dumbbell and $893.04 \mathrm{~N}$ with $10.7 \mathrm{~kg}$ dumbbell. It was shown that the rate of increase of load was $78.3 \%$, the rate of increase of peak joint moment was $57.7 \%$ and the rate of increase of peak muscle force was $38.3 \%$ comparing exercises with $6 \mathrm{~kg}$ and $10.7 \mathrm{~kg}$ dumbbells.

Maximum strain was calculated as $4.44 \mathrm{~mm} / \mathrm{mm}$ with $6 \mathrm{~kg}$ dumbbell and calculated as $6.42 \mathrm{~mm} / \mathrm{mm}$ with $10.7 \mathrm{~kg}$ dumbbell. Considering the stress, mean of the $\sigma_{\max }$ was $4.85 \mathrm{MPa}$ and $7.46 \mathrm{Mpa}$, respectively. In addition, peak value of the $\sigma_{\max }$ was $7.76 \mathrm{Mpa}$ and $10.66 \mathrm{Mpa}$, respectively. When comparing two different load of exercise, the rate of increase of maximum stress was $44.4 \%$ and the rate of increase of maximum strain was $37.3 \%$. Considering the strain and the stress results, it is understood that the strain and the stress on the tendon is greater. This is due to the different material properties of the tendon tissue.

It is seen that there is no linear correlation with increasing load (from $6 \mathrm{~kg}$ to $10.7 \mathrm{~kg}$ ) considering the results of muscle force, joint moment, strain and stress. Although the motion analysis results of the two different loads are similar, the mechanical response of the biceps brachii is different for the two dumbbell loads. Peak moment of elbow joint increased by $57.7 \%$ while peak muscle force increased by $38.3 \%$. This is because the muscle moment arm distance changes during the dumbbell curl exercise. The percentage increase in strain and stress is also different ( $44.4 \%$ and $37.3 \%$ respectively). This is due to the nonlinear characteristics of the muscle-tendon complex.

According to the results of this study, it is understood that increasing exercise load will not affect the muscle contraction at the similar rate. Bryanton et al. (2012) showed that there was no correlation between increasing of barbell load and muscle effort significantly by measuring EMG of squat exercise. Besides, Zink et al. (2006) showed that peak muscle force was associated with loads of 40 and $50 \%$ of one repetition maximum by measuring EMG of squat exercise. This study also indicates similar results for dumbbell curl exercise.

\section{Conclusion}

Firstly, the motion analysis of the dumbbell curl exercise was performed in this study. The inverse dynamic model was simulated according to the motion data and the joint moment was calculated. Then, the biceps brachii force was calculated considering the muscle moment arm change. After that, structural analyses of the biceps brachii were examined with a simplified finite element model. It is understood that there is no linear correlation between dumbbell load and the mechanical response of the muscle considering the results of muscle force, strain and stress. Therefore, it could be said that increasing load in strength exercise does not have a significant impact on muscle growth. 
A simplified finite element model is used in the study. However, this model is considered to be sufficient since the two dumbbell loads are examined relatively.

\section{Declarations}

\section{Conflict of interest}

The authors declare that they have no known competing financial interests or personal relationships that could have appeared to influence the work reported in this paper.

\section{Ethical approval}

The study was approved by the Sakarya University Ethical Committee. The ethics approval number was 71522473/050.01.04/94.

\section{References}

1. Agyapong-Badu, S., Warner, M., Samuel, D., Stokes, M., (2016) Measurement of ageing effects on muscle tone and mechanical properties of rectus femoris and biceps brachii in healthy males and females using a novel hand-held myometric device. Archives of Gerontology and Geriatrics 62, 59-67. https://doi.org/10.1016/j.archger.2015.09.011

2. Al-Obaid Y.F., Bangash F.N., Bangash, T., (2007) Trauma - An Engineering Analysis with Medical Case Studies Investigation. Springer-Verlag, Berlin.

3. Blemker, S.S., Pinsky, P.M., Delp, S.L., (2005) A 3D model of muscle reveals the causes of nonuniform strains in the biceps brachii. Journal of Biomechanics 38, 657-665. https://doi.org/10.1016/j.jbiomech.2004.04.009

4. Bol, M., Reese, S., (2008) Micromechanical modelling of skeletal muscles based on the finite element method. Computer Methods in Biomechanics and Biomedical Engineering 11, 489-504. https://doi.org/10.1080/10255840701771750

5. Brown, D. (2008) Tracker Video Analysis and Modeling Tool. Retrieved from http://www.opensourcephysics.org/items/detail.cfm?ID=7365

6. Bryanton, M.A., Kennedy, M.D., Carey, J.P., Chiu, L.Z.F., (2012) Effect of squat depth and barbell load on relative muscular effort in squatting. Journal of Strength and Conditioning Research 26, $2820-$ 2828. https://doi.org/10.1519/JSC.0b013e31826791a7

7. Cadova, M., Vilimek, M., Daniel, M., (2014) A comparative study of muscle force estimates using Huxley's and Hill's muscle model. Computer Methods in Biomechanics and Biomedical Engineering 17, 311-317. https://doi.org/10.1080/10255842.2012.683426

8. Cha, G., Kim, K., Hong, D., Chung, W., (2015) Muscular Activity Analysis of Haptic-based Resistance Training Machine Compared with Dumbbell Training. International Journal of Precision Engineering and Manufacturing 16, 1209-1213. https://doi.org/10.1007/s12541-015-0156-4 
9. Chandler, R.F., Clauser, C.E., McConville, J.T., Reynolds, H.M., Young, J.W., (1975) Investigation of inertial properties of the human body. Aerospace Medical Research Laboratory, Technical Report DOT-HS-017-2-315-1A.

10. Delp, S.L., Anderson, F.C., Arnold, A.S., Loan, P., Habib, A., John, C.T., Guendelman, Thelen, E.D.G., (2007) OpenSim: Open-Source Software to Create and Analyze Dynamis Simulations of Movement. IEEE Transactions on Biomedical Engineering 54, 1940-1950.

https://doi.org/10.1109/TBME.2007.901024

11. García-Manso, J.M., Rodríguez-Matoso, D., Sarmiento, S., de Saa, Y., Vaamonde, D., Rodríguez-Ruiz, D., Da Silva-Grigoletto, M.E., (2012) Effect of high-load and high-volume resistance exercise on the tensiomyographic twitch response of biceps brachii. Journal of Electromyography and Kinesiology 22, 612-619. https://doi.org/10.1016/j.jelekin.2012.01.005

12. Giat, Y., Mizrahi, J., Levine, W.S., Chen, J., (1994) Simulation of distal tendon transfer of the biceps brachii and the brachialis muscles. Journal of Biomechanics 27, 1005-1014. https://doi.org/10.1016/0021-9290(94)90217-8

13. Hwang, H.J., Chung, W.H., Song, J.H., Lim, J.K., Kim, H.S., (2016) Prediction of biceps muscle fatigue and force using electromyography signal analysis for repeated isokinetic dumbbell curl exercise, Journal of Mechanical Science and Technology 30, 5329-5336. https://doi.org/10.1007/s12206-0161053-1

14. Karimi, M.T., Hemmati, F., Mardani, M.A., Sharifmoradi, K., Hosseini, S.I., Fadayevatan, R., Esrafilian, A., (2021) Determination of the correlation between muscle forces obtained from OpenSim and muscle activities obtained from electromyography in the elderly. Physical and Engineering Sciences in Medicine 44, 243-251. https://doi.org/10.1007/s13246-021-00973-9

15. Lewis, G., Shaw K.M., (1997) Modeling the tensile behavior of human Achilles tendon. Bio-Medical Materials and Engineering 7, 231-244. https://doi.org/10.3233/BME-1997-7402

16. Martins, J.A.C., Pato, M.P.M., Pires, E.B., (2006) A finite element model of skeletal muscles. Virtual and Physical Prototyping 1, 159-170. https://doi.org/10.1080/17452750601040626

17. Nolte, N., Krüger, P.E., Els, P.S., (2011) Three dimensional musculoskeletal modelling of the seated biceps curl resistance training exercise. Sports Biomechanics 10, 146-160. https://doi.org/10.1080/14763141.2011.577441

18. Oomens, C.W.J., Maenhout, M., van Oijen, C.H., Drost, M.R., Baaijens, F.P., (2003) Finite element modelling of contracting skeletal muscle. Philosophical Transactions of the Royal Society B Biological Sciences 358, 1453-1460. https://doi.org/10.1098/rstb.2003.1345

19. Rohrle, O., Sprenger, M., Schmitt, S., (2017) A two-muscle, continuum-mechanical forward simulation of the upper limb. Biomechanics and Modelling in Mechanobiology 16, 743-762. https://doi.org/10.1007/s10237-016-0850-x

20. Stiggins, C., Allsen, P., (1985) Exercise methods notebook 19. National Strength and Conditioning Association Journal 7, 77. 
21. Tang , G., Qian, L.W., Wei, G.F., Wang, H.S., Wang, C.T., (2012) Development of software for human muscle force estimation. Computer Methods in Biomechanics and Biomedical Engineering 15, 275283. https://doi.org/10.1080/10255842.2010.527835

22. Trinler, U., Schwameder, H., Baker, R., Alexander, N., (2019) Muscle force estimation in clinical gait analysis using AnyBody and OpenSim. Journal of Biomechanics 86, 55-63.

https://doi.org/10.1016/j.jbiomech.2019.01.045

23. van den Bogert, A.J., Geijtenbeek, T., Even-Zohar, O., Steenbrink, F., Hardin, E.C., (2013) A real-time system for biomechanical analysis of human movement and muscle function. Medical \& Biological Engineering \& Computing 51, 1069-1077. https://doi.org/10.1007/s11517-013-1076-z

24. Webb, J.D., Blemker, S.S., Delp, S.L., (2014) 3D finite element models of shoulder muscles for computing lines of actions and moment arms. Computer Methods in Biomechanics and Biomedical Engineering 17, 829-837. https://doi.org/10.1080/10255842.2012.719605

25. Winter, D.A., (1990) Biomechanics and Motor Control of Human Movement. Wiley, New York.

26. Winters, J.M., Woo, S.L.Y., (1990) Multiple Muscle Systems Biomechanics and Movement Organization. Springer-Verlag, New York.

27. Zink, A.J., Perry, A.C., Robertson, B.L., Roach, K.E., Signorile, J.F., (2006) Peak power, ground reaction forces, and velocity during the squat exercise performed at different loads. Journal of Strength and Conditioning Research 20, 658-664. https://doi.org/10.1519/R-16264.1

\section{Figures}

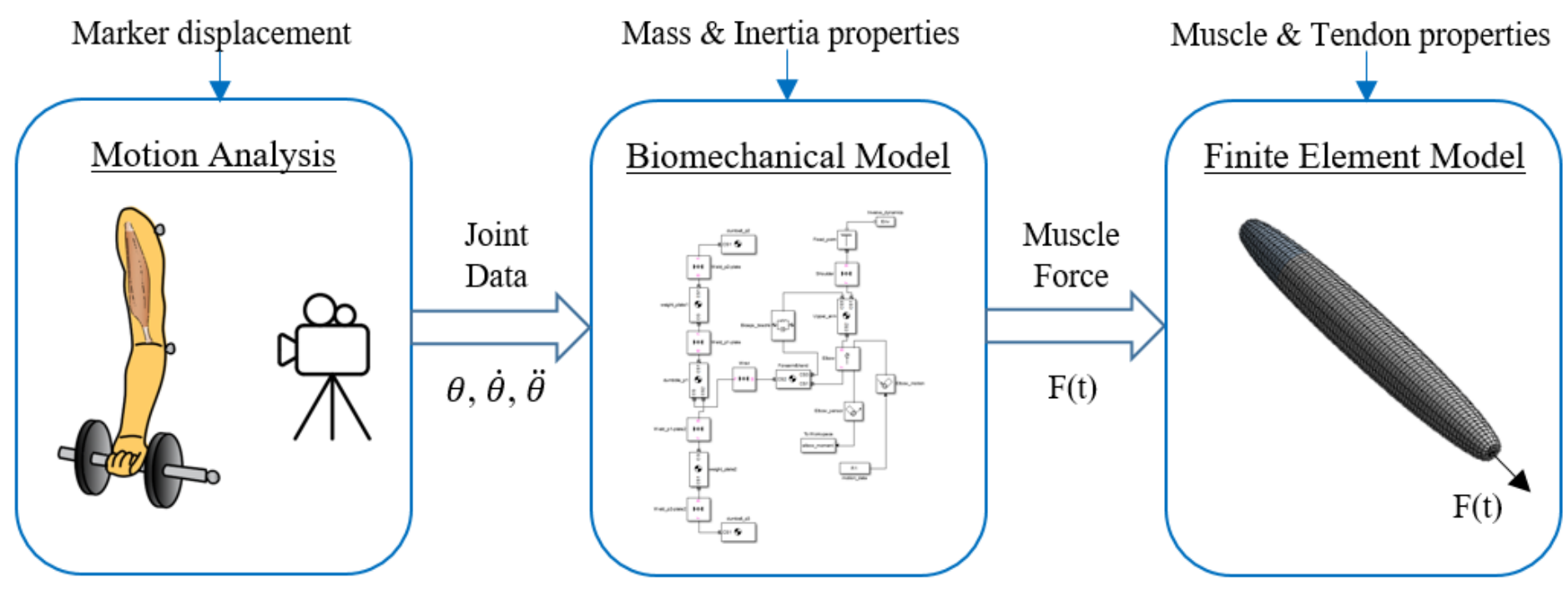

\section{Figure 1}

The flowchart of research methodology. 


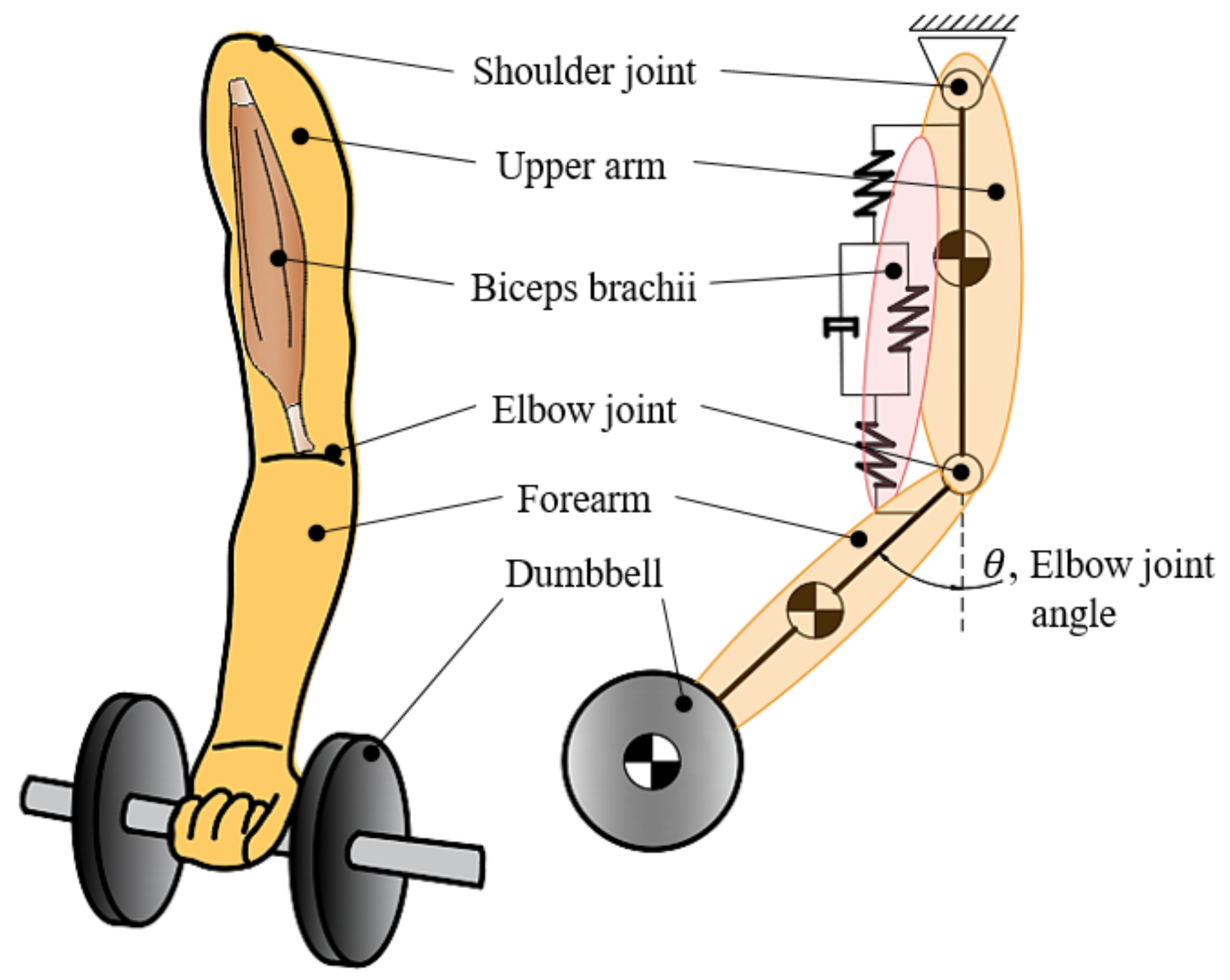

Figure 2

Left; physiological model, right; mechanical model of the dumbbell curl. 


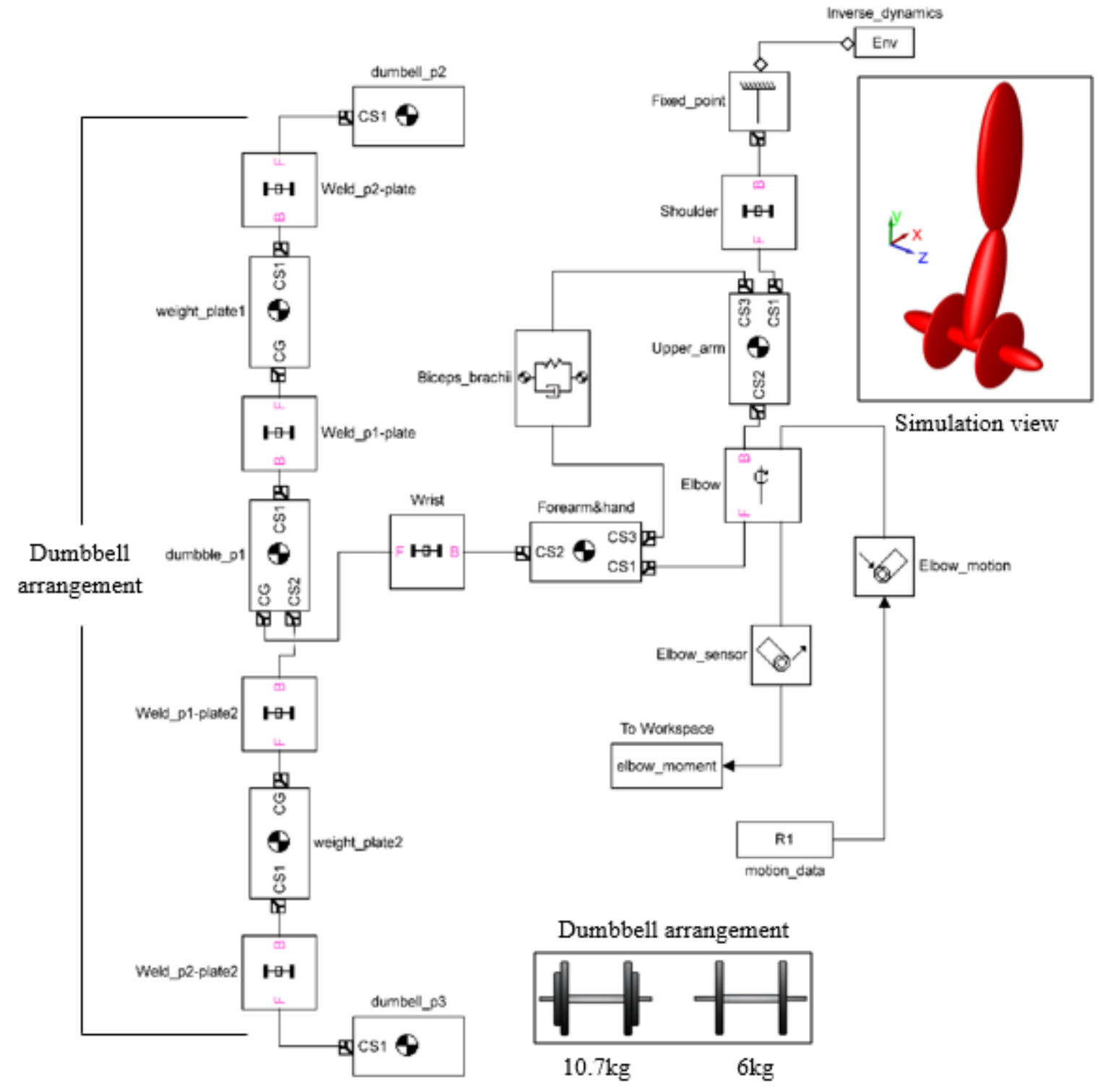

Figure 3

Inverse dynamic model of the dumbbell curl
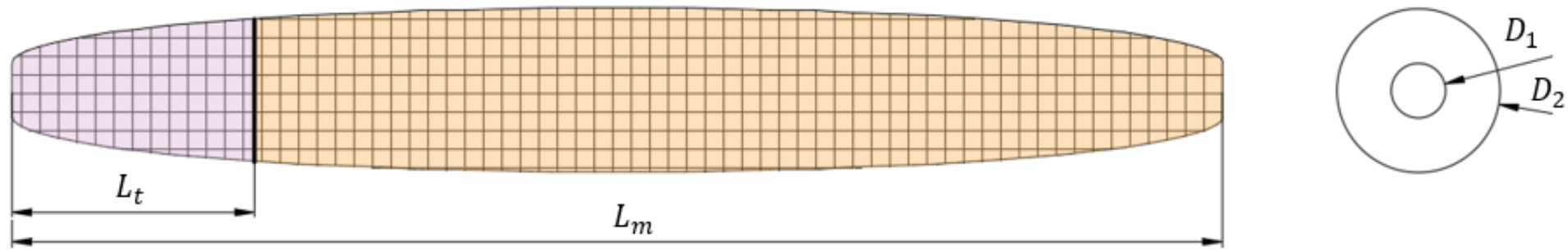

Figure 4 

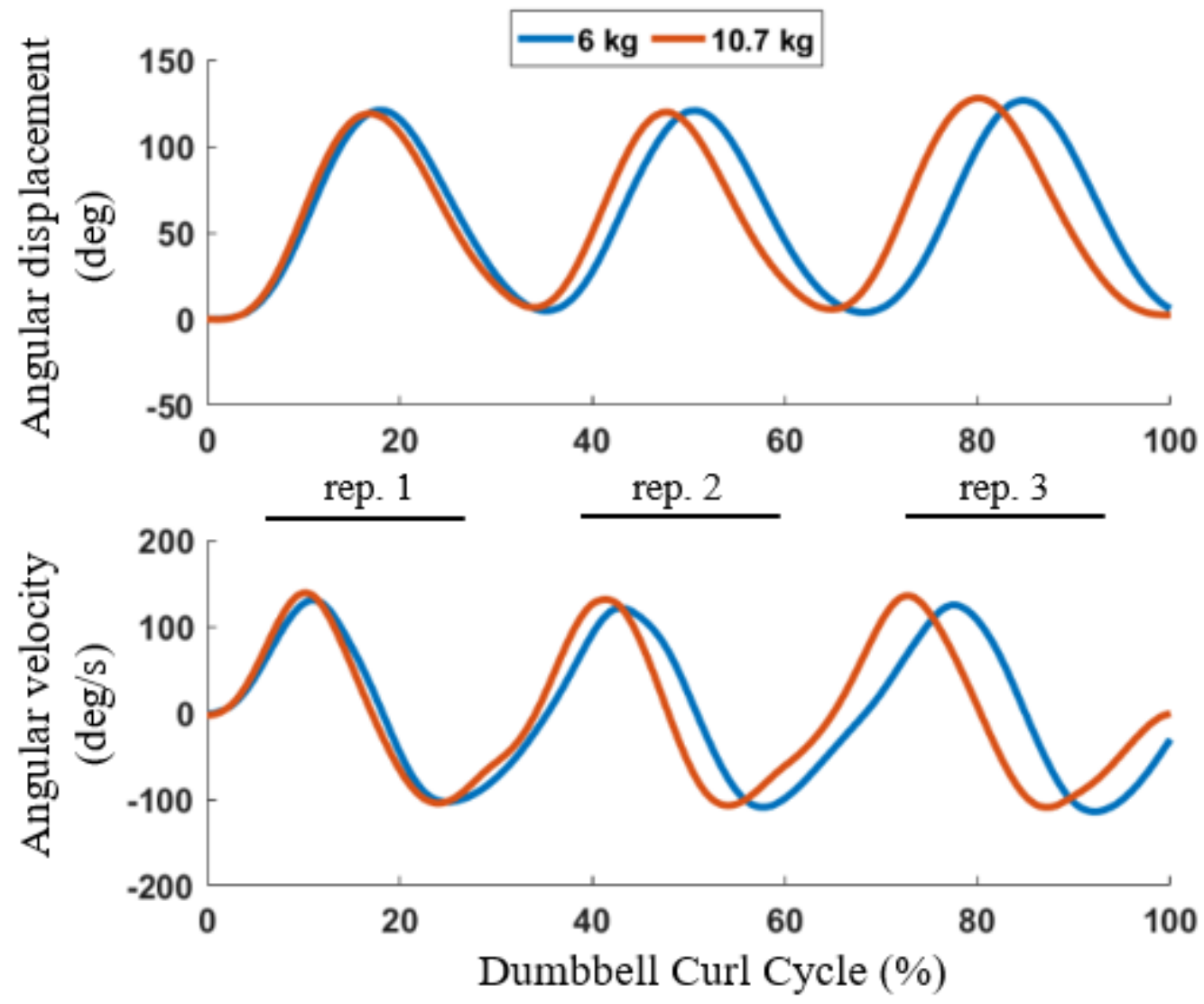

Figure 5

Displacement (top) and velocity (bottom) of elbow joint. rep; repeat 


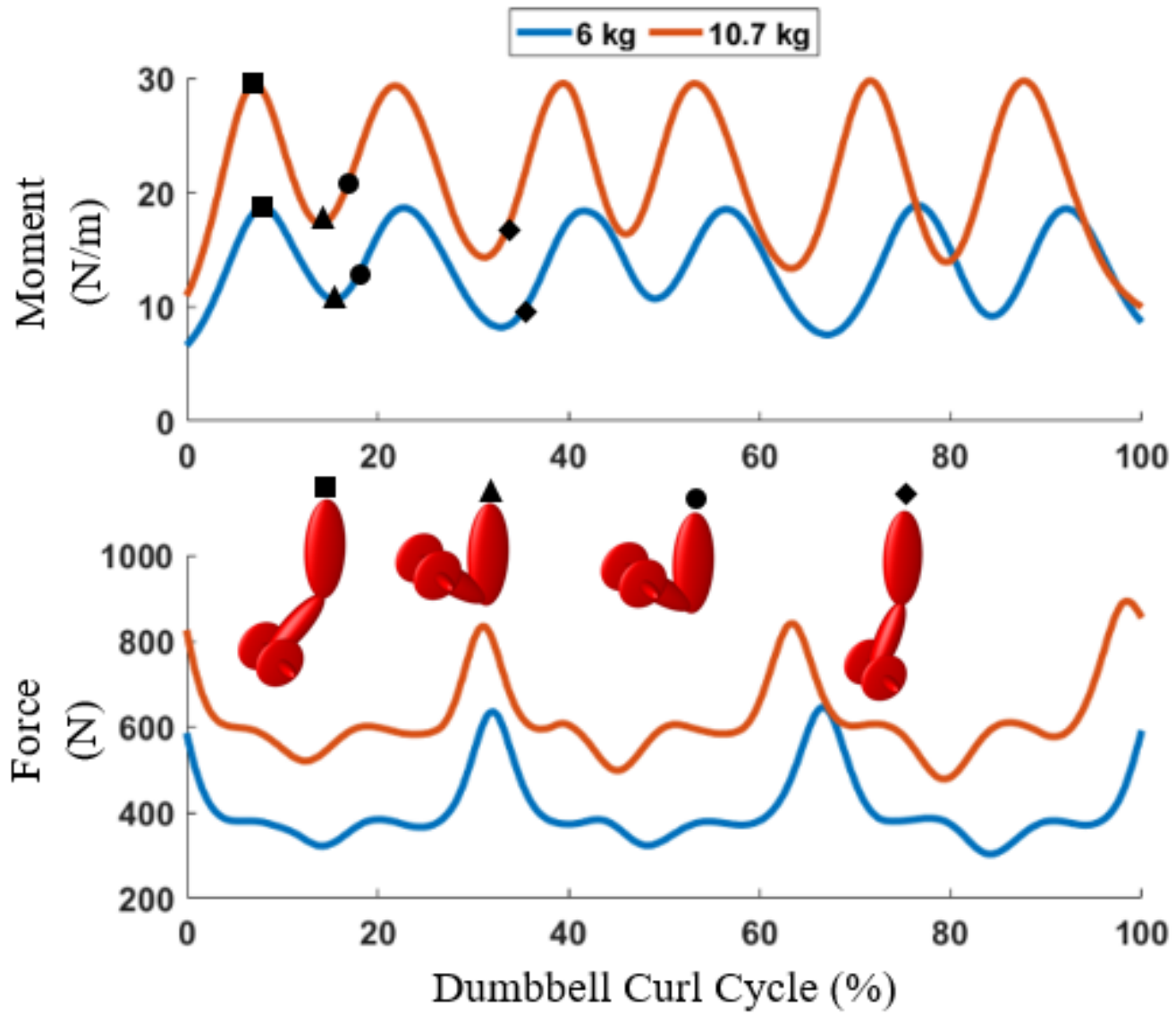

Figure 6

Elbow joint moment and muscle force of biceps brachii with different load.
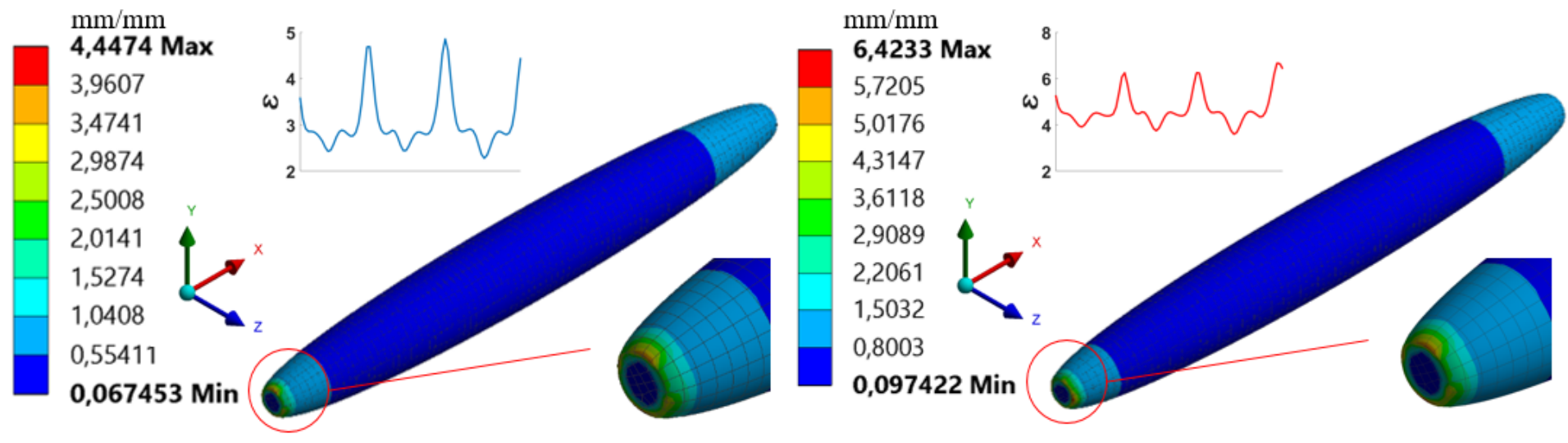

Figure 7

Force-dependent strain behaviour of biceps brachii. Left; $6 \mathrm{~kg}$, right; $10.7 \mathrm{~kg}$ 


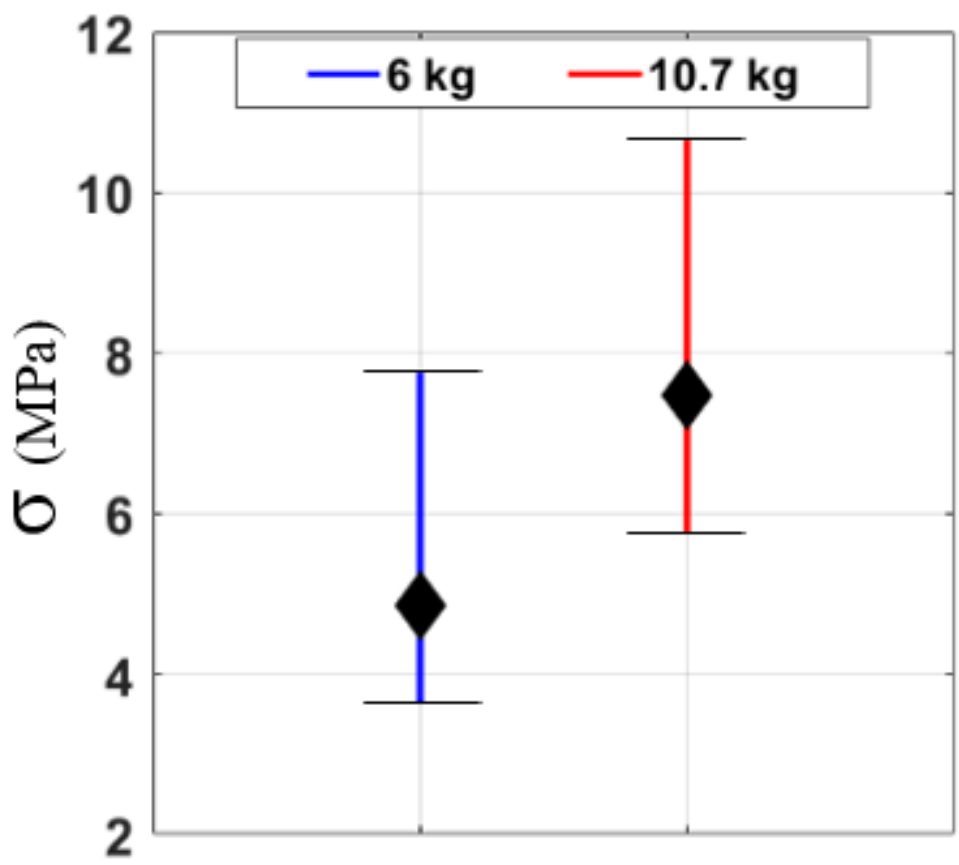

Figure 8

Equivalent stress of biceps brachii 